\title{
Online to On Stage: Towards a performative approach to interpreter education
}

\author{
Richard Bale
}

\begin{abstract}
Spoken language interpreting is a complex task involving comprehension of a source language message and subsequent production of this in the target language, all of which happens at a fast pace and often in front of an audience. Building on research conducted in language learning and drama-based pedagogies, this paper takes stock of recent technological developments in interpreter education, and proposes that a renewed focus on the interpreter as a language user and as a performer is necessary. ${ }^{1}$
\end{abstract}

\section{Introduction}

Modern-day interpreters are required to be versatile and able to adapt to different working environments. Not only are interpreting professionals employed at large international conferences, but more and more frequently, they are called upon to mediate in hospitals, business meetings, police stations, courtrooms and prisons. This means that those seeking a career as an interpreter can no longer expect to do their job from the security of an interpreting booth; they will often be visible in front of an audience and will therefore be expected to perform.

In considering the notion of performance in interpreting, it is first useful to decide how this term is to be understood in the context of interpreter education and practice. In performance theory, Schechner (2003: 8) explains that some of the important characteristics of performance include the presence of an audience, a demonstration of skills and abilities, and a high degree of self-awareness on the part of the performer. Fleming (2016: 195) contextualises these characteristics within drama teaching by stating that this provides:

a more nuanced account of performance that does not always have to mean literally performing on stage but refers rather to the phenomenology of the experience, the element of self-consciousness and in-built reflection that marks it out from everyday experience.

\footnotetext{
${ }^{1}$ This paper is a revised version of an invited talk given at the Department of Interpretation and Translation, University of Bologna, Forlì on 13 November 2013.
} 
This interpretation of performance is of use when developing a performative approach to interpreter education. Interpreters do not literally perform on stage but carry out their role in front of spectators, whether these are other interlocutors, conference delegates or other interpreters. An interpreter must constantly monitor her/his performance to ensure the accuracy and adequacy of the message conveyed, and so a high degree of self-awareness and reflection plays a key role in any interpreter-mediated event. Furthermore, there is an added performative dimension involved with any act of language mediation, particularly when interpreting, since the interpreter is not the architect of the original, or source, message and must therefore decide, somewhat creatively, how to transfer this message appropriately to the other language and culture.

The complex nature of spoken language interpreting means that the work of an interpreter is cognitively demanding, bringing with it a high level of stress and anxiety, working under what Kohn and Kalina (1996) describe as "adverse conditions" for such a cognitively demanding communicative activity. Interpreting can be distinguished from other language mediation tasks, such as written translation, by its immediacy and its live, real-time presentation. The interpreter must employ active listening skills whilst simultaneously translating and delivering an oral (or sign language) message in another language. These are the adverse conditions referred to by Kohn and Kalina, and in such a fast-paced communicative context, the interpreter may feel some degree of anxiety and nervousness. The pressure to perform, often in front of an audience, exacerbates this high level of anxiety, and hence it is necessary to address this in interpreter education. It is difficult, however, to replicate these conditions realistically in the classroom, and so it is questionable whether current pedagogical methods adequately prepare interpreters for the real challenges of the task at hand. Aspects of performance will necessarily become a crucial part of an interpreter's education, and it is therefore vital that future interpreting pedagogy strives to equip student interpreters with the skills to deal with such a pressured working environment before they enter the profession.

This paper starts by outlining the current issues in interpreter education and recent technological developments which have led to the creation of new and exciting computer-based, online materials. It is then argued that, whilst the contribution of new technologies and a focus on the interpreter's strategic behaviour is undoubtedly important, it is also necessary to emphasise the performative aspects of human interaction, which play a central role in interpreting scenarios.

\section{Issues and trends in interpreter education}

Interpreter education has traditionally been characterised by a teacher-led model, with students relying on the instructor as the central source of information and expertise, and the main supplier of supplementary resources to be used outside the classroom. This traditional approach was also hampered by a lack of training materials at the appropriate level. For example, students 
would select their own materials to use during self-study (e.g. YouTube videos), many of which were not necessarily suitable for interpreters at the beginning of their training.

As Gorm Hansen \& Shlesinger (2007) pointed out several years ago, reduced contact hours on many university programmes led to an increased focus on self-study, and they called for technology-assisted resources to enable students to retain access to a high standard of education by allowing learners to work more independently. This new emphasis on self-study and learner autonomy resulted in a focus on student learning rather than didactic teaching. This also shifted the emphasis onto the study of the various modes of interpreting. Traditionally, simultaneous interpreting has been seen as the gold standard, and has therefore been foregrounded in training programmes.

At this point, it is useful to draw clear distinctions between the various modes of interpreting. In spoken language interpreting, the simultaneous mode, in which the interpreted rendition is uttered at the same time as the source message, technical equipment is required to enable the interpreter to work in a sound-proof booth, where s/he can produce the target text for listeners, who receive the target language rendition through headphones. As Pöchhacker (2004: 19) points out, simultaneous interpreting is usually the mode of choice for sign language interpreters, as there is no audible overlap between source and target message.

However, simultaneous interpreting is just one of several modes used in various contexts. In consecutive interpreting, for example, the source speaker delivers a speech in segments of between three and 12 minutes in length. The interpreter usually takes notes and then provides a target language rendition (cf. Kohn \& Kalina 1996). This type of interpreting might also be conducted bi-directionally using so-called dialogue or liaison interpreting (cf. Smirnov 1997; Mason 2014), where the interpreter provides interpretation in two language directions. Such bilingual communicative events can take place in a wide variety of settings, such as business meetings, legal proceedings and patient-doctor consultations, among many others. In these contexts, it is clear that the interpreter is visible to all interlocutors. This is very much in contrast to simultaneous interpreting, where the interpreter is heard but rarely seen. It is understandable, therefore, that the focus in training programmes has been on the cognitive processes and strategies required by interpreters when dealing with two languages at speed and under pressure. Nevertheless, with interpreters now used in many settings where they are visible to an audience, it is necessary not only to teach students to act strategically, but also to focus on aspects of their performance.

As mentioned above, deficiencies in interpreter training used to be due to a lack of resources which students could use to practise interpreting independently. The response has largely been to provide students with more online and technology-assisted resources, which enable students to practise using language strategically in interpreting contexts. The next section provides a brief overview of recent developments in technology-enhanced approaches to 
interpreter training.

\section{Developments in technology-enhanced interpreter training}

As outlined above, the focus in interpreter training programmes has been on students' ability to act strategically when under pressure. It has long been acknowledged that trainee interpreters require ample opportunity to practise interpreting outside the classroom. There has therefore been much work in recent years devoted to the development of self-study resources, many of which make use of new technologies.

\subsection{Learning online}

Since the early 1990s, the use of computer-based training resources has enjoyed increased attention. Researchers drew in particular on insights from Computer Assisted Language Learning (CALL), and investigated the possibility of developing Computer Assisted Interpreter Training (CAIT) resources (cf. Sandrelli 2003; Sandrelli 2005). Such resources were mainly for offline use, for example in CD ROM-format, which represented the first systematic efforts to create resources at an appropriate level and for use by students independently.

Since the advent of CAIT, there have been rapid developments in the use of new technologies, moving from offline, computer-assisted tools to online resources. Many universities have created their own speech repositories, some of which are publicly available. ${ }^{2}$ One example of a large speech bank is the Marius project, which involved researchers at the University of Granada recording and categorising around 2000 speeches (de Manuel Jerez 2003; Sandrelli \& de Manuel Jerez 2007). The European Commission also hosts a large speech repository with real and simulated speeches, which can be searched according to language, domain, interpreting mode and level of linguistic complexity. ${ }^{3}$ The repository includes a recording function so that students can upload their interpreting performance to receive feedback from an online tutor.

There has also been much interest in virtual learning, moving from the use of established virtual learning environments, such as moodle and Blackboard to specialised platforms tailor-made for interpreter education. For example, the Virtual Institute at the University of Geneva offers a blended-learning approach with interactive, online content combined with face-to-face training sessions (cf. Seeber 2006). Other projects have developed 3D virtual learning environments using Second Life, for example (cf. Şahin 2013). Notable work here has been carried out at the University of Surrey in the IVY (Interpreting in Virtual Reality)

\footnotetext{
${ }^{2}$ See for example the online speech bank of the University of Geneva: http://live.fti. unige.ch/.

${ }^{3}$ Available at: https://webgate.ec.europa.eu/sr/.
} 
and EVIVA (Evaluating the Education of Interpreters and their Clients through Virtual Learning Activities) ${ }^{4}$ projects (cf. Braun et al. 2015; Braun \& Slater 2014; Braun et al. 2013). The VLE can be used in various modes, where the student can practise interpreting and record her/his performance; or in live mode, which enables all users - students, tutors, clients - to come together to simulate an interpreting scenario, such as in a courtroom or at a hospital.

The examples above give a brief insight into the development of training opportunities in recent years, moving from offline, computer-assisted tools to online, asynchronous and synchronous possibilities. We will now explore briefly corpus-based resources for interpreter training.

\subsection{Corpus-based pedagogic approaches}

Another key area of development in technology-enhanced interpreter training has been in the use of electronic corpora. To distinguish this term from the early paper-based corpora, here we use corpus to refer to a "body of machine-readable text" (McEnery \& Wilson 2001: 197), many of which can include written and spoken texts; they can be multimodal; they are searchable; and for the purposes of language learning, translation and interpreting, corpora are usually multilingual.

In recent years, several projects have led to the creation of corpora for use in learning contexts - originally in language learning and, more recently, in interpreting and translation. Educators noted early on, however, that the potentially rich linguistic resources found in a corpus need to be rendered user-friendly for learners and teachers by undergoing some form of "pedagogic mediation", as Widdowson (2003) puts it. One such corpus is Backbone, ${ }^{5}$ which was initially compiled for language learning purposes (cf. Kohn 2012), and then used alongside online learning activities on moodle in undergraduate interpreting classes (cf. Bale 2013; Bale 2015).

Other examples of corpora designed specifically for interpreter training have also emerged over the last decade. For example, the European Parliament Interpreting Corpus (EPIC), compiled at the University of Bologna, contains European Parliament speeches in English, Italian and Spanish, together with the interpreted renditions in each of these languages, enabling students to search within original texts and/or explore interpreted texts (cf. Bendazzoli \& Sandrelli 2005; Bendazzoli \& Sandrelli 2009).

There are also interpreting corpora which consist of texts in particular domains. The Directionality in Simultaneous Interpreting (DIRSI) corpus contains conference speeches about health-related topics, and students are able to hear interpreters' performances both from and into the native language, i.e. from $\mathrm{A}$ to $\mathrm{B}$ and $\mathrm{B}$ to $\mathrm{A}$ language. The FOOTIE corpus, on the other

\footnotetext{
${ }^{4}$ IVY / EVIVA project website: http://virtual-interpreting.net/working-in-ivy-ve/ live-mode.

5 Accessible at http://webapps.ael.uni-tuebingen.de/backbone-search/faces/ initialize.jsp; jsessionid=9FD8BC00DE4B119C9E762EA4D55DD5A7.
} 
hand, consists of speech output from football press conferences, involving both one-to-one and one-to-many Q\&A sequences interpreted into English, Italian, French and Spanish (cf. Bendazzoli \& Sandrelli 2009).

This brief review of technology-enhanced, corpus-based and online approaches to interpreter training exemplifies the level of attention this field has received in recent years. Such new training approaches undoubtedly address some of the issues outlined above, such as a lack of training materials at an appropriate level, and the over-reliance on interpreting trainers. However, in focusing so strongly on computer-based training materials, it is possible that training programmes neglect to address the more holistic aspects of an interpreter's performance, which, particularly in contexts where the interpreter is visible in front of an audience, are just as important as the ability to think and act strategically.

\section{From online to on stage: drama-based pedagogies}

So far, it has become apparent that the interpreter training landscape has been enriched by technological advances in materials and curriculum design. However, with the contexts in which interpreters work also becoming more and more diverse, it is necessary to examine not only how an interpreter functions on a cognitive and strategic level, but also how s/he interacts within the complex, social space of an interpreted communicative event. Owing to the performance aspect of interpreting, mentioned above, attention is now turned to performance and drama-based pedagogy.

\subsection{Drama-based pedagogy in other disciplines}

The benefits of drama-based pedagogy have been recognised in various disciplines for some time now. In the field of business, for example, there is a growing body of research on the role of theatre-based training for business executives and other personnel in customer-facing roles (cf. for example, Steed 2005; Aponte-Moreno 2014). Much of the work in drama-based business, management and leadership education has been inspired by the Brazilian theatre director, Augusto Boal, whose Theatre of the Oppressed movement (cf. Boal 1979) emphasised the use of performance and theatre techniques to instigate change. For example, in Management Education, Monks et al. (2001) drew on Boal's techniques to empower aspiring managers and leaders to assume positions of authority and control - perhaps ironic considering Boal's explicitly anti-establishment leanings.

Possibly the most notable contribution to drama-based learning comes from interpreting and translation's neighbouring discipline of language learning. In particular, learner anxiety, and the use of drama techniques to mitigate the effects of this anxiety, has already been researched extensively. Leaver et al. (2005: 98) liken this so-called foreign-language anxiety to performance anxiety and the feelings of stage fright often experienced by actors and actresses. 
This has given rise to the exploration of pedagogical approaches which use techniques from drama and theatre studies in the foreign language learning classroom.

The very fact that the journal Scenario was established as an outlet for research and discussion about the topic of drama and language learning is also testament to the growing interest in performative teaching and learning in foreign and second language contexts. The use of drama in the language classroom now has rather a long history, with Schewe and Shaw's (1993) volume Towards Drama as a Method in the Foreign Language Classroom paving the way for a new research discipline. Prior to this, practitioners and scholars in English language teaching, more specifically, noted the benefits of drama techniques as early as the 1970s, with Maley and Duff's collection of drama techniques for language teachers first published in 1978, and now in its third edition (cf. Maley \& Duff 2005).

Interest in drama-based pedagogy shows no signs of waning, with many scholarly societies and academic journals announcing calls for contributions to conferences and special journal issues on themes related to arts-based learning and drama techniques in a wide range of learning contexts, from the development of compassion and understanding in healthcare professionals (Jack \& Tetley 2016) to the learning of science in secondary education (Braund 2014).

\subsection{Anxiety and creative performance}

The link highlighted above between foreign language anxiety and performance anxiety is even more apparent in the context of interpreter education. Certain parallels exist between interpreting and the performing arts, both of which require a stage-worthy presentation of content and an ability to think quickly and creatively in an improvisatory way (Horváth 2010: 153). The ability to improvise is arguably more necessary in interpreting than in the performing arts, since there is little or no opportunity to rehearse beforehand. Bendazzoli (2009) also highlights the importance of public speaking and voice training, and advocates theatrical training as a means of improving trainees' interpreting performance. Nevertheless, there is as yet little empirical evidence to support the use of drama-based pedagogies in the interpreting classroom, despite the apparent parallels between performance and interpreting.

The case of anxiety is worthy of closer consideration, as interpreters often experience some degree of nervousness, especially during training and at the beginning of their career. It has traditionally been thought that trainee interpreters simply need to gain extensive practice and experience in order to overcome and learn to control anxiety. However, a study on anxiety in consecutive interpreting by Jiménez and Pinazo (2001) suggests that the effects of stress and anxiety can be mitigated with targeted training. The researchers tested three hypotheses:

1. The greater the fear of public speaking, the greater the level of anxiety; 
2. The greater the fear of public speaking, the poorer the interpreting performance;

3. The greater the anxiety, the poorer the interpreting performance.

In the study, 197 trainee interpreters were asked to complete a consecutive interpreting task of 6-8 minutes in length, with the original speaker delivering the source language speech in three segments of 2-3 minutes each. Before starting the task, the students were asked to complete two questionnaires: an edited form of the confidence in public speaking questionnaire (cf. Carillo et al. 1999) and the STAI questionnaire (cf. Spielberger, Gorsuch \& Lushene 1988) - used to ascertain an individual's temporary state of anxiety in a particular situation. The results showed that only hypothesis 1 was confirmed, with no significant negative correlation between fear of public speaking, greater levels of anxiety and poorer interpreting performance. Fear and anxiety alone, therefore, do not lead to deficient interpreting performance. The authors conclude that trainee interpreters may be able to mitigate potential negative effects of anxiety by focusing on the resources at their disposal, as well as a belief that they can complete the task to a sufficiently high standard (Jiménez and Pinazo 2001: 115). These resources may refer to tangible skills acquired during training, such as active listening, paraphrasing and note-taking, but may also relate to creative skills, such as the ability to improvise and perform in front of an audience. It is this notion of creativity which is perhaps not addressed by using the abundance of online and computer-based materials which have been developed in recent years.

In order to be creative, trainee interpreters need to be placed in situations where they can take risks. This has previously been done by role-playing mock conferences and other interpreted scenarios, or in some cases, students have been placed in muted booths so that they can interpret at real conferences but without having their interpretation heard by any of the delegates. This no doubt has its merits, but as the student is placed either in an artificial situation or in a real scenario but without their performance being heard by anyone, it cannot be said that there is any real risk, and in turn the level of anxiety is likely to be lower and opportunities to experiment with creative approaches are decreased. One possible solution is to provide opportunities for students to perform in low-stakes but nevertheless real interpreting situations. For example, the speech which provided the basis for this current paper, was delivered in English at the University of Bologna, Forlì, and students simultaneously interpreted into Italian. This was a real situation in that the speaker was not invited for the purposes of facilitating interpreting practice, and the interpreters' performances were heard by delegates, which in turn provided a scenario in which students could test their creativity while interpreting, with the risk of making errors in front of real delegates. Nevertheless, this situation was low-risk, as this was not an international, professional conference, where errors could lead to significant problems. In this realistic situation, students were able to test their reaction 
to anxiety and, after the event, they could analyse their own real-life creative performance and identify areas for improvement.

\subsection{Performance aspects in interpreter training}

As seen from the overview in section 3 above, the development of online and computer-based resources for interpreter education has provided trainers and students with increased amounts of materials at appropriate levels of difficulty, both for use in the classroom and for self-study. These resources facilitate news ways for students to practise the various skills required as an interpreter. However, as argued above, some of the qualities relating to creative thinking, public speaking and performance cannot be honed using online exercises alone - qualities such as awareness of body (language), non-verbal communication, coping with anxiety and stage fright, presentation skills, a sense of audience, to name but a few. As we have seen in section 4.1, the use of drama techniques in various disciplines, notably in language learning, has featured prominently for many years. With the recent focus on cognitive approaches and strategic behaviours in interpreting, both of which can be trained using new technologies and online resources, it is perhaps appropriate to also emphasise the skills required by an interpreter as a whole person.

There are already some examples of training programmes and scholars focusing on soft skills and the interpreter's ability to interact and perform. The Department of Interpretation and Translation at Bologna, Forlì, offers a module in Techniques of Oral Presentation which, though does not take an explicitly drama-based approach to learning, nevertheless enables students to engage with performative aspects of their interpreting practice by exploring public speaking, verbal and non-verbal communication, voice, breathing and facial expressions, among other aspects.

Perhaps the most notable work has been carried out at the University of Bologna, where the Theater in Language - Language in Theater (TiLLiT) approach has been in use since 2004, and was awarded the European Language Label in 2014 in recognition of its contribution as a new initiative in language learning. In a summary of some of the students' experiences with the TiLLiT approach, Fernández García et al. (2012) draw on four areas in which theatre-based learning was employed, namely theatre and information technology, theatre and translation skills, the role of Malinche in the training of intercultural mediators, and theatre and the exile experience in translator training. Here, it would be useful to highlight the experience of the student involved in theatre and translation, Angelo Nestore, who explored the role of the theatrical experience in enabling a student to acquire translation skills (Nestore 2008). According to Nestore, he became more attuned to the creative processes involved with mediation between two languages and cultures, and the following transferrable skills were developed as a result of his engagement with the TiLLiT approach (Fernández García et al. 2012: 79-80):

- Bilingual communicative competence 
- Extralinguistic competence (bicultural knowledge)

- Professional competence (organisational skills and team working)

- Psycho-physiological competence (relating to cognition and behaviour)

- Transfer competence (in this case, the process of transferring an original text into a translated message)

- Strategic competence, applying strategic behaviours, conscious and unconscious, and employing verbal and non-verbal skills to solve problems.

As the authors point out, these skills would almost certainly be acquired by any student of translation, but it is the focus on creativity and the cultural and human aspects of source-target text transfer which adds a further dimension for learners who engage with a drama-based approach. The case studies presented in Fernández García et al. (2012) do not address interpreter education explicitly, but it is possible to see how such an approach could also add an emotional and performance dimension to the training of interpreters.

The shift that is called for in this paper from a purely strategic and cognitive view of interpreting to a more holistic notion of an integrated, creative and performative process does indeed already have support from some scholars in the field (cf. Horváth 2010; Bahadır 2009; Bendazzoli 2009). Bendazzoli has been involved with the TiLLiT approach at the University of Bologna and describes interpreting explicitly as a creative activity, as follows: "The ability to activate strategies, i.e. to make rapid decisions on how to best deliver the message and solve possible problems, is nothing but a creative process" (Bendazzoli 2009: 155). It would now be beneficial to capitalise on the momentum created in drama-based learning in other disciplines, such as language learning, and to formulate a coherent approach to incorporating drama, creativity and performance into the interpreter education curriculum.

\section{Summary and next steps}

This paper has outlined some of the key developments in the online and computer-based methods for the training of interpreters, highlighting the abundance of materials which have been created in recent years, enabling students to practise interpreting with appropriate resources. However, it was noted that new technologies in training contexts have flourished alongside the increased emphasis on training students' ability to act strategically in interpreting scenarios. Whilst this is undoubtedly of great importance, interpreter educators and researchers must not lose sight of the fact that interpreting is a highly dynamic and interactive communicative activity. Particularly in contexts where the interpreter is visible to the interlocutors and spectators, it is vital that aspects 
of performance and delivery receive as much attention in the curriculum as the technical skills and strategic behaviours which are required by an interpreter.

It was then argued that insights from drama-based learning in other disciplines, most notably in language learning, could provide a useful framework for training content which focuses on the interpreter as a whole person. Indeed, as mentioned above, the University of Bologna, Forlì already has a history of theatre-based learning for language students, including those studying translation and interpreting.

For a relatively young discipline, there is already an extensive body of scholarship in interpreting studies broadly and in interpreter education in particular. As shown in Figure 1, the training landscape has moved from offline methods, both with and without the use of computers; to the development of online and interactive resources, such as corpora and virtual learning environments; to blended approaches to learning, which represents the pedagogical approach used in most interpreter training programmes today. To optimise and strengthen the quality of training further, we suggest that a holistic view be taken when designing interpreting curricula, focusing on the interpreter not just as a linguist, but as a whole person at the heart of a complex, dynamic and exciting intercultural mediation.

As has been discussed above, there is already some interesting work on performance and theatrical skills in interpreting, and it seems that drama-based learning may offer a useful method for preparing students to engage confidently and proficiently in dynamic and interactive interpreting scenarios, where they are highly visible to all parties involved in the communicative activity. However, as yet, there is no sustained and coherent body of research which explores the benefits, and indeed shortcomings, of drama-based learning in interpreting. Taking into consideration Schewe's (2013: 18) view that performative teaching and learning "should be used as an umbrella term to describe (the various culturally-specific) forms of foreign language teaching that derive from the performing arts", the development of a performative approach to interpreter education requires empirical studies to ascertain the types of activities from the performing arts which might be beneficial in the education of interpreters. Without such empirical evidence, several questions are left unanswered, such as how notions of performance can contribute to a holistic approach to interpreter education? How can drama-based and performance skills be embedded in the curriculum? Or would stand-alone modules or series of workshops be more appropriate? With the advances in new technologies and the creation of new and exciting materials in recent years, it is now incumbent on the interpreting research and education community to build on this success by returning to a focus on interpreters as people, emphasising the highly spontaneous, dynamic and performative nature of human interaction in interpreter-mediated events. 


\section{Bibliography}

Aponte-Moreno, Marco (2014): Embodying Authentic Leadership. In: Schuyler, Kathryn Goldman; Baugher, John Eric; Jironet, Karin \& Lid-Falkman, Lena (eds.): Leading with Spirit, Presence, and Authenticity: A Volume in the International Leadership Association Series, Building Leadership Bridges. San Francisco: Wiley/Jossey-Bass, 197

Bahadır, Şebnem (2009): Body-and-enactment-centred Interpreting Pedagogy: Preliminary Thoughts on a Train-the trainers Concept for (Medical) Interpreting. In: Andres, Dörte \& Pöllabauer, Sonja (eds.): Spürst Du wie der Bauch rauf-runter. Munich: Peter Lang, 29-43

Bale, Richard (2015): An Evaluation of Spoken Corpus-based Resources in Undergraduate Interpreter Training. In: International Journal of Applied Linguistics 25/1, 23-45

Bale, Richard (2013): Undergraduate Consecutive Interpreting and Lexical Knowledge: The Role of Spoken Corpora. In: The Interpreter and Translator Trainer 7/1, 27-50

Bendazzoli, Claudio (2009): Theatre and Creativity in Interpreter Training. In: Fernández García, María Isabel; Zucchiatti, Marie-Line \& Biscu, Maria Giovanna (eds.): L'esperienza teatrale nella formazione dei futuri mediatori linguistici e culturali. Bologna: BUP, 153-164

Bendazzoli, Claudio \& Sandrelli, Annalisa (2009): Corpus-based Interpreting Studies: Early Work and Future Prospects. In: Tradumàtica: Traducció $i$ Tecnologies de la Informació i la Comunicació 7, 1-9

Bendazzoli, Claudio \& Sandrelli, Annalisa (2005): An Approach to Corpus-based Interpreting Studies: Developing EPIC (European Parliament Interpreting Corpus). In: MuTra - Challenges of Multidimensional Translation: Conference Proceedings. Saarbrücken, 1-12

Boal, Augusto (1979): Theater of the Oppressed. London: Pluto Press (Transl. Charles A. \& Maria-Odilia Leal McBride \& Emily Fryer)

Braun, Sabine; Slater, Catherine \& Botfield, Nicholas (2015): Evaluating the Pedagogical Affordances of a Bespoke 3D Virtual Learning Environment for Training Interpreters and Their Clients. In: Ehrlich, Suzanne \& Napier, Jemina (eds.): Interpreter Education in the Digital Age: Innovation, Access, and Change. Special volume of the Interpreter Education Series. Washington, D.C.: Gallaudet University Press

Braun, Sabine \& Slater, Catherine (2014): Populating a 3D Virtual Learning Environment for Interpreting Students with Bilingual Dialogues to Support Situated Learning in an Institutional Context. In: The Interpreter and Translator Trainer 8/3, 469-485

Braun, Sabine; Slater, Catherine; Gittins, Robert; Ritsos, Panagiotis \& Roberts, Jonathan (2013): Interpreting in Virtual Reality: Designing and Developing a 3D Virtual World to Prepare Interpreters and Their Clients for Professional 
Practice. In: Kiraly, Don \& Hansen-Schirra, Silvia (eds.): New Prospects and Perspectives for Educating Language Mediators. Tübingen: Narr, 93-120

Braund, Martin (2014): Drama and Learning Science: An Empty Space? In: British Educational Research Journal 41/1, 102-121

Carrillo, Francisco Javier Méndez; Saura, Cándido J. Inglés \& Montesinos, María Dolores Hidalgo (1999): Propriedades Psicométricas del Cuestionario de Confianza para Hablar en Público: Estudio con una Muestra de Alumnos de Enseñanzas Medias. In: Psicothema 11/1, 65-74

De Manuel Jerez, Jesús (ed.) (2003): Nuevas Tecnologías y Formación de Intérpretes. Granada: Atrio

Fernández García, María Isabel; Ariza, Mercedes; Bendazzoli, Claudio; Biscu, Maria Giovanna \& Grimaldi, Yvonne (2012): The Effective Action of Theatre in the Educational Mapping of Linguistic and Intercultural Mediators. In: Scenario 6/2, 75-86

Fleming, Mike (2016): Exploring the Concept of Performative Teaching and Learning. In: Even, Susanne \& Schewe, Manfred (eds.): Performatives Lehren, Lernen, Forschen. Performative Teaching, Learning, Research. Berlin: Schibri, 189-205

Gorm Hansen, Inge \& Shlesinger, Miriam (2007): The Silver Lining: Technology and Self-study in the Interpreting Classroom. In: Interpreting 9/1, 95-118

Horváth, Ildikó (2010): Creativity in Interpreting. In: Interpreting 12/2, 146-159

Jack, Kirsten \& Tetley, Josie (2016): Using Poems to Explore the Meaning of Compassion to Undergraduate Nursing Students. In: International Practice Development Journal 6/1, 1-13

Jiménez Ivars, Amparo \& Pinazo Calatayud, Daniel (2001): "I failed because I got very nervous". Anxiety and Performance in Interpreter Trainees: An Empirical Study. In: The Interpreters' Newsletter 11, 105-118

Kohn, Kurt (2012): Pedagogic Corpora for Content and Language Integrated Learning. Insights from the BACKBONE Project. In: The Eurocall Review $20 / 2,3-22$

Kohn, Kurt \& Kalina, Silvia (1996): The Strategic Dimension of Interpreting. In: Meta 41/1, 118-138

Leaver, Betty Lou; Ehrman, Madeline \& Shekhtman, Boris (2005): Achieving Success in Second Language Acquisition. Cambridge: CUP

Maley, Alan \& Duff, Alan (2005): Drama Techniques. A Resource Book of Communication Activities for Language Teachers ( ${ }^{\text {rd }}$ ed.). Cambridge: CUP

Mason, Ian (ed.) (2014): Triadic Exchanges: Studies in Dialogue Interpreting ( $2^{\text {nd }}$ ed.). London: Routledge

McEnery, Tony \& Wilson, Andrew (2001): Corpus Linguistics: An Introduction. Edinburgh: EUP 
Monks, Kathy; Barker, Patricia \& Ní Mhanacháin, Aoife (2001): Drama as an Opportunity for Learning and Development. In: Journal of Management Development 20/5, 414-423

Nestore, Angelo (2008): L'esperienza del laboratorio teatrale in lingua e la formazione del traduttore. Unpublished BA thesis, University of Bologna at Forlì

Pöchhacker, Franz (2004): Introducing Interpreting Studies. London: Routledge

Sandrelli, Annalisa (2005): Designing CAIT (Computer-Assisted Interpreter Training) Tools: Black Box. In: MuTra - Challenges of Multidimensional Translation, Saarbrücken 2-6 May 2005. Conference Proceedings - EU High Level Scientific Conference Series. Proceedings of the Marie Curie Euroconferences. http://www. euroconferences.info/proceedings/2005_ Proceedings/2005_Sandrelli_Annalisa.pdf [last accessed June 15, 2016]

Sandrelli, Annalisa (2003): New Technologies in Interpreter Training: CAIT. In: Gerzymisch-Arbogast, Heidrun; Hajičová, Eva; Sgall, Petr; Jettmarová, Zuzana; Rothkegel, Annely \& Rothfuß-Bastian, Dorothee (eds.): Textologie und Translation, Jahrbuch Übersetzen und Dolmetschen 4, 261-293

Sandrelli, Annalisa \& de Manuel Jerez, Jesús (2007): The Impact of Information and Communication Technology on Interpreter Training: State-of-the-art and Future Prospects. In: The Interpreter and Translator Trainer 1/2, 269-303

Schechner, Richard (2003): Performance Theory. London: Routledge

Schewe, Manfred (2013): Taking Stock and Looking Ahead: Drama Pedagogy as a Gateway to a Performative Teaching and Learning Culture. In: Scenario $12 / 1,5-27$

Schewe, Manfred \& Shaw, Peter (1993): Towards Drama as a Method in the Foreign Language Classroom. Frankfurt: Peter Lang

Seeber, Killian (2006): SIMON: An Online Clearing House for Interpreter Training Materials. Society for Information Technology \& Teacher Education International Conference 1, 2403-2408

Smirnov, Stanislav (1997): An Overview of Liaison Interpreting. In: Perspectives: Studies in Translatology 5/2, 211-226

Spielberger, Charles Donald; Gorsuch, Richard L. \& Lushene, Robert E. (1988): Cuestionario de Ansiedad Estado-Rasgo. Adaptación Española, Sección de Estudio de Tests. Madrid: TEA Ediciones

Steed, Robert (2005): The Play's the Thing: Using Interactive Drama in Leadership Development. In: Journal of Business Strategy 26/5, 48-52

Widdowson, Henry (2003): Defining Issues in English Language Teaching. Oxford: OUP 